\title{
PRELIMINARY STUDY OF THE EFFECT OF USING BIOSORBENTS ON THE POLLUTION OF THE TREATED WATER
}

ALTAHER H. ${ }^{1,2, *}$

Received: 06/03/2014

Accepted: 29/05/2014

Available online: 05/06/2014
${ }^{1}$ Chemical Engineering Technology Department Yanbu Industrial College P.O. Box 30436, Saudi Arabia

${ }^{2}$ Current address: British University in Egypt Chemical Engineering Department, Cairo, Egypt

\section{ABSTRACT}

Several adsorbents have been tried out by researchers to remove different pollutants from wastewater. However, the adverse effect of these biosorbents on the treated water and the possibility of leaching new pollutants to the treated water have not been investigated. A batch technique was employed to study this phenomenon. Three agricultural wastes namely sawdust, dates stones and palm fibers were investigated. The possible leaching of total dissolved solids (TDS) and organic compounds in the form of chemical oxygen demand (COD) from these substances to water were investigated. The effect of water $\mathrm{pH}$ and particle size of these biosorbents on the extent of the leaching process was studied. The results indicate high release of both TDS and COD for the three biosorbents. A COD value as high as $230 \mathrm{mg} \mathrm{l}^{-1}$ was obtained, while the highest TDS leached was $29 \mathrm{mg} \mathrm{l}^{-1}$. DS was found to have the highest leaching ability, followed by SD and PF. The highest leaching was obtained at high $\mathrm{pH}$ and small particle size of the adsorbent.

Keywords: Adsorption, Date Stones, leaching, Palm fibers, Saw dust, COD, TDS

\section{Introduction}

Water is one of the most vital natural resources on the earth. However, rapid industrialization and urbanization have resulted in the production of huge amount of wastewater containing all types of pollutants. Increasing of environmental awareness has led to more stringent regulations on the quality of water and wastewater. This has led to search for appropriate techniques to cope with these limits. Various techniques have been developed by researchers for treatment of such wastewater. The real challenge is to select the efficient, economic technique that has the least adverse effect on the environment. The treatment method may be physical, chemical or biological in nature. Examples of the treatment methods include; foam filtration, filtration, ion exchange, sedimentation, solvent extraction, adsorption, chemical oxidation, membrane processes (Bhatnagar and Minocha, 2006), stepwise coagulation, GAC/O3 oxidation (Qian et al., 2013), Fenton process (Zhang et al,. 2012), lime softening (Varga et al., 2013), coagulation, electrochemical processes (Ahmad et al., 2012), electrocoagulation (Muthukumaran and Beulah, 2010), chemical precipitation (Rathinam et al., 2010).

Altaher H. (2014), Preliminary study of the effect of using biosorbents on the pollution of the treated water, Global NEST Journal, 16(4), 707-716. 
These methods have some drawbacks; including low efficiency for removal of trace concentration of pollutants in case of chemical/biological oxidation, electrolysis, ion exchange and solvent extraction (Bhatnagar and Minocha, 2006; Zhang et al., 2012). Coagulation and precipitation processes produce large amount of sludge and require $\mathrm{pH}$ control. Furthermore, ozonation will remove color from wastewater without decreasing the COD (Bhatnagar and Minocha, 2006; Ahmad et al., 2012). Membrane processes suffer from the problem of fouling of the membrane used (Dang et al., 2009). Many of these processes lack in cost effectiveness, energy intensive processing and the low removal efficiency for some pollutants (Rathinam et al., 2010).

On the other hand, adsorption has many advantages on the other processes. This process has the characteristics of convenience, easy operation and simplicity in design (Bhatnagar and Minocha, 2006). It has a wide application for removal of different pollutants (Bhatnagar and Minocha, 2006; Ansari and Mosayebzadeh, 2010). Other important advantages of this process include: low operation cost, high flexibility, simple design and operation, easy automation, lack of sensitivity to toxic pollutants and the capability of operation at very low concentration, environmentally friendly, less investment in terms of initial cost (Ansari and Mosayebzadeh, 2010; Auta and Hameed, 2013; Galán et al., 2013; Ismail et al., 2013).

The most important criteria in adsorption processes is to find a low cost adsorbent that is widely available, having high adsorption capacity, possess rapid rate of removal and having low adverse effect on the treated water. Many adsorbents have been investigated.

Historically, activated carbon was the primary adsorbent of use because of its high capacity for removal of various pollutants (Jambulingam et al., 2007). The major disadvantage of using this adsorbent is its high price and its high regeneration cost (Ahmaruzzaman, 2008). This has led researchers to look for more economic adsorbents. Large variety of materials have been investigated including; natural zeolites, sludge, red mud, siliceous materials, peat, chitin and chitosan (Ahmaruzzaman, 2008), polyaluminum hydroxide, diatomaceous earth, clay mineral, dolomitic sorbents (Khan et al., 2009), magnetic composite, nano particles (Sheela et al., 2012), chitosan-activated carbon composite (Auta and Hameed, 2013) and organo bentonite (Koyuncu et al., 2011).

Another alternative was to investigate the possibility of using agro-based inexpensive material as adsorbents. These wastes represent two problems; their disposal and being unused resources (Bhatnagar and Minocha, 2006). Tremendous amounts of these materials are produced every year. Bansal et al., (2009) used rice husk to remove nickel ions from aqueous solutions. Garg et al., (2008) used sugarcane bagasse for the same purpose. Jayarajan et al., (2011) investigated the use of Jackfruit peels for removal of Rhodamine dye. Gram husk and groundnut were tried by Chakrabarti et al., (2008) for treatment of water polluted with other textile dyes. Khan et al., (2004) mentioned the use of rice husk, sugarcane bagasse, sawdust, soybean hull, cottonseed hulls, rice barn and straw for the removal of different pollutants.

Other examples of agricultural wastes that have been searched are pistachio hull (Moussavi and Khosravi, 2011), chemically modified coir pith (Suksabye and Thiravetyan, 2012), cedar saw dust (Ismail et al., 2013), crushed brick, garlic peal (Fan et al., 2012), rice husk, peanut shell, barks and dry tree leaves, tea and coffee wastes, wheat bran (Madrakian et al., 2012), mango peel waste (Sheela et al., 2012), apple pomace (Mundhe et al., 2012), jack fruit waste, brewery waste (Anagnostopoulos et al., 2012; Anagnostopoulos and Symeopoulos, 2013) treated sugar cane bagasse, yellow passion fruit peel, jack fruit leaf powder, coconut husk, pine saw dust (Mundhe et al., 2012), and tree products such as fern (Carro et al., 2010).

All these agricultural wastes have the same main chemical compositions namely; cellulose, hemicelluloses, lignin and extractives. Cellulose and hemicelluloses are carbohydrate polymers constituents of simple sugars monomers. Cellulose is the major chemical component of fiber with the degree of polymerization from (DP) from 5,000 to 20,000. The cellulose fibers are held together with hemicellulose and lignin. Hemicelluloses have lower DP (only 50-300) with side groups on the chain molecule and are essentially amorphous. Lignin is 
a phenyl-propene aromatic compound that cannot be fermented but can be used as a high-energy content boiler fuel. Lignin acts as cementing material between the cellulose and hemicellulose and as a stiffening agent within the fibers. In the production of chemical wood pulps, it is dissolved by various chemical processes, leaving the cellulose and hemicelluloses behind in fibrous form.

Although the cellulose structure is the same in different species, the hemicelluloses vary considerably among species and especially between hardwoods and soft-woods (Browning, 1975; Wyman et al., 2005; Wahab et al., 2013).

To the best of the author knowledge, based on extensive literature survey, none of the researchers discussed the adverse effect of such adsorbents on the treated water. The main focus of the researchers was measuring the adsorption capacity of such adsorbents, investigating the different factors affecting the adsorption process and applying thermodynamic, kinetic and equilibrium models to explain the adsorption process. None of the researchers studied the possible drawbacks of using these biosorbents on the treated water. The goal of this research is to investigate the effect of using biosorbents on the treated wastewater. Three adsorbents namely; dates stone, palm fibers and saw dust were investigated. The effect of dose of adsorbents, $\mathrm{pH}$ and particle size on the leaching of soluble substances and on the chemical oxygen demand were investigated.

\section{Materials and methods}

\subsection{Adsorbents}

Three agricultural wastes were tested; dates stones (DS), Palm fibers (PF) and sawdust (SD). Dates stones were collected from local food processing plant in Madinah, Saudi Arabia. The fibers were collected locally from different types of palm trees and the saw dust was collected from the local sawmills. The method that is usually followed by different researchers for preparation of the adsorbents was applied in this research. The agricultural wastes were washed with tap water to remove dust and any foreign materials (with good rubbing in case of dates stones and palm fibers), filtered out and then soaked in distilled water for ten minutes and filtered out again. The raw materials were oven-dried at $105^{\circ} \mathrm{C}$ overnight. The raw materials were ground separately in kitchen mixer. They were then sieved to different sizes and kept in covered glass containers for further use.

\subsection{Effect of mass of adsorbent}

Different known masses of every absorbent were added to $50 \mathrm{ml}$ aliquot of distilled water. The mixtures were agitated using shaker (IKA Yellowline RS/OS 10 Control) for 3 hours at $250 \mathrm{rpm}$, left to settle for 20 minutes. The solutions were filtered out and filtrates were tested for TDS and COD.

\subsection{Effect of $\mathrm{pH}$ of water}

The effect of initial pH was studied by preparing 3 sets of $150 \mathrm{ml}$ conical flasks containing $50 \mathrm{ml}$ of distilled water. The $\mathrm{pH}$ of water in each flask was adjusted at different value using either $1 \mathrm{~N} \mathrm{H}_{2} \mathrm{SO}_{4}$ or $1 \mathrm{~N} \mathrm{NaOH}$. To each series, $0.12 \mathrm{~g}$ (weighed to the fourth decimal point) of one adsorbent were added. The mixtures were agitated for 3 hours and left to settle for 20 minutes. The mixtures were filtered and the filtrate was analyzed for TDS and COD.

\subsection{Effect of adsorbent particle size}

To study the effect of the adsorbent particle size on the leaching process, three sets of $150 \mathrm{ml}$ conical flasks were used (one set for each adsorbent). Every set consisted of 6 flasks (one flask for every particle size). 50 $\mathrm{ml}$ aliquots of distilled water were added to every flask in the sets. To each flask in the set, $0.14 \mathrm{~g}$ (weighed 
to the fourth decimal point) of the appropriate adsorbent were added. The flasks were agitated for 3 hours at $250 \mathrm{rpm}$ left to settle for 20 minutes and filtered out. The filtrate was analyzed for TDS and COD.

\subsection{Analytical method}

The chemical oxygen demand (COD) of the water after the agitation process was determined following Hach $^{\circledR}$ Method 8000 of the Hach Water Analysis Handbook (Hach, 1997), using DRB200 Reactor and DPR 890 colorimeter. Total dissolved solids (TDS) were measured using SevenEasy conductivitimeter from Metler Toledo and $\mathrm{pH}$ was measured using $\mathrm{pH}$ 501, EuTech Instruments. All experiments were performed in a duplicate bases and the average was taken.

\section{Results and discussion}

\subsection{Effect of adsorbent mass}

Many organic and inorganic compounds may be leached from different agricultural wastes depending on the nature and structure of this waste. Examples of these organic compounds include carbohydrates, proteins, and lipids (Hansen and Cheong, 2007). As illustrated by Figure 1, increasing the mass of waste resulted in increase in the amount of dissolved solids extracted to the water used. That implies in real situations that when using such agricultural wastes in high quantities to treat industrial wastewater then we are removing a certain pollutant from such water. However, we are adding a new threat to this water. It is clear that a substantial concentration of dissolved solids is extracted from the three tested wastes. The highest concentration is obtained from PF and DS for all used masses, respectively.

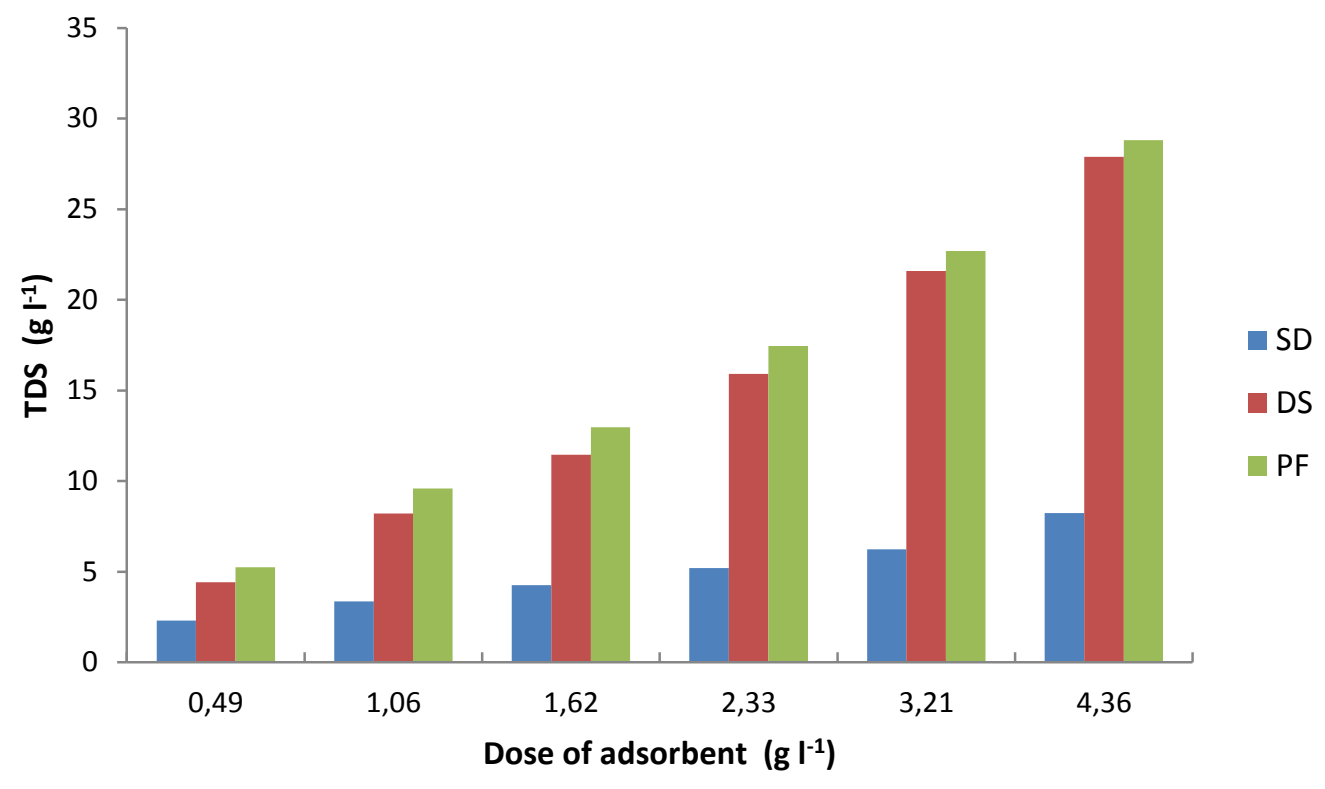

Figure 1. Effect of adsorbent dose on TDS leached to the water

Figure 2 indicates the relationship between the dose of the adsorbent and the amount of TDS leached to the water. It is clear that correlation coefficient, $R^{2}$, is greater than 0.99 for all adsorbents which assure the close relationship. 


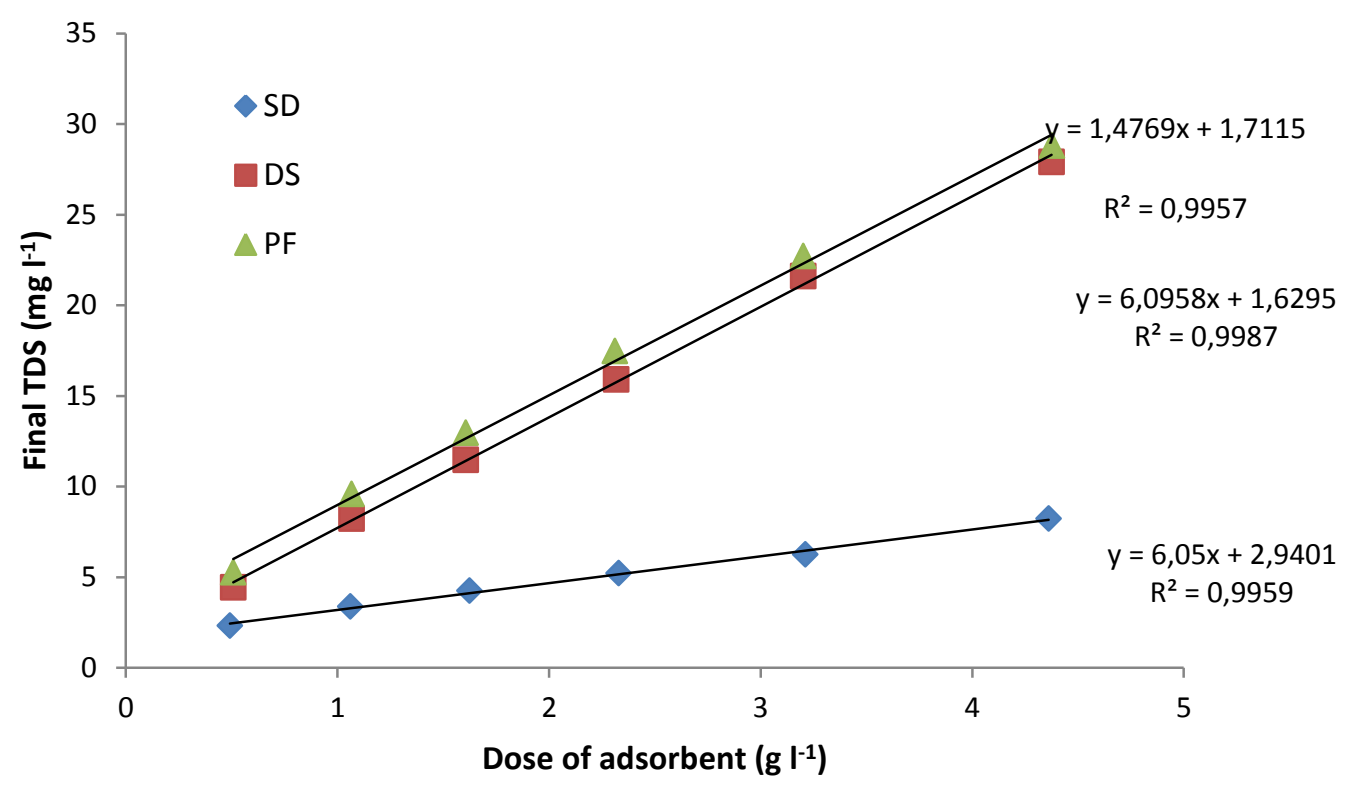

Figure 2. Correlation between the adsorbent dose and TDS extracted to the water

As illustrated by Figure 3 high COD values are obtained when analyzing the treated water which indicates that a considerable part of the dissolved solids are organic material. Again the concentration of these organic materials is directly proportional to the dose of the agricultural waste applied. One important threat of these organic materials is the ability to chelate (Salati et al., 2010) with the heavy metals that may be initially present in the treated water thus decreasing their removal efficiency from water.

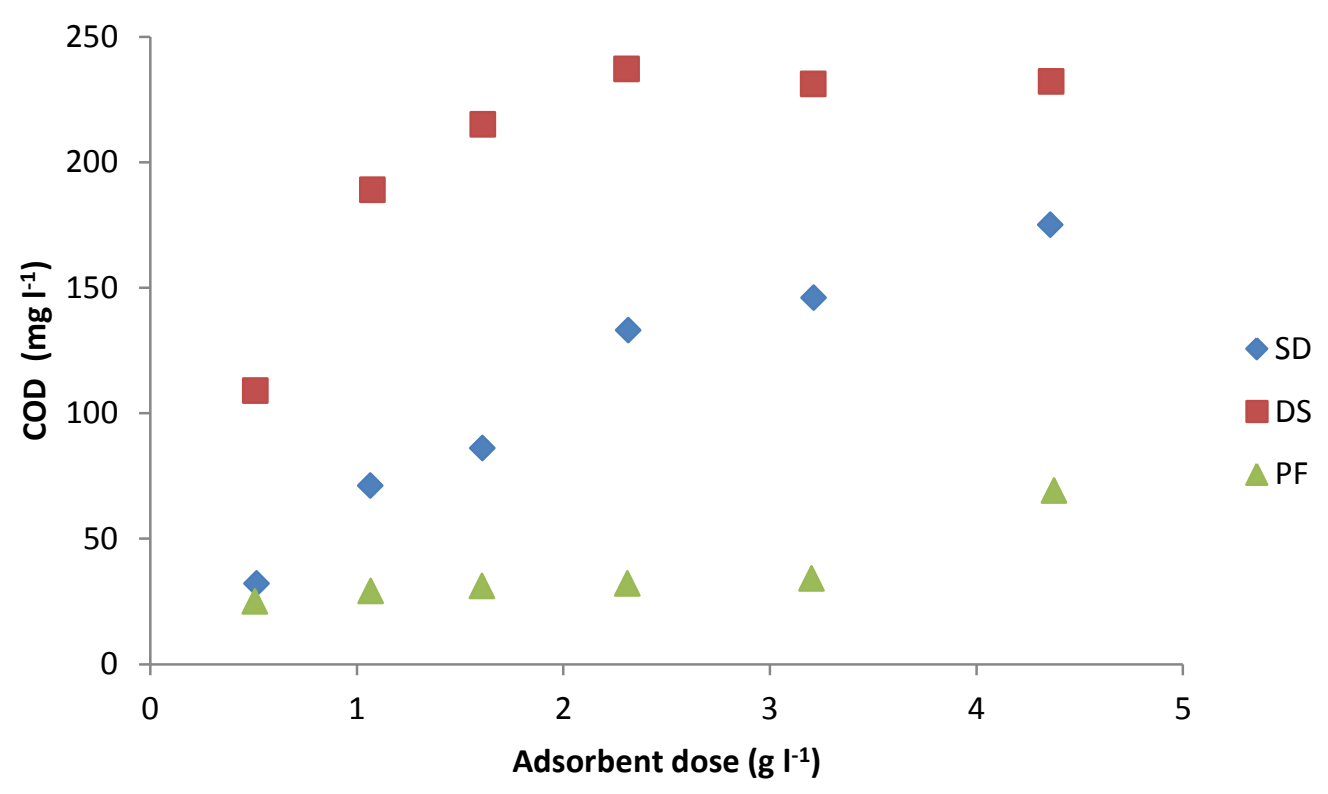

Figure 3. Effect of adsorbent dose on COD leached to the water 


\subsection{Effect of $\mathrm{pH}$}

As indicated by Lai and Idris (2013), the chemical constituents of most lignocellulosic materials are polymeric carbohydrates, which consist of cellulose, hemicellulose, and lignin. Figure 4 indicates that the $\mathrm{pH}$ of the water did not have a significant effect on the extraction of the organic compounds unless at very high $\mathrm{pH}$ value ( $\mathrm{pH}$ 12). Usually the extraction of hemicelluloses and lignin is performed at alkaline $\mathrm{pH}$ at elevated temperature (Johar et al., 2012). However even at room temperature some of the hemicelluloses and lignin have been extracted (Borrega et al., 2013). The $\mathrm{pH}$ of the wastewater is related to the activity producing this wastewater. For instance, $\mathrm{pH}$ of the textile wastewater is fluctuating from 6-10 (Kalra et al., 2011). The pH of the wastewater produced from olive mill has a range 4.6-5.8 (Kılıç and Solmaz, 2013). Refinery wastewater may have a value of 8.5 (Yan et al., 2014). Biodiesel wastewater has high pH due to the significant levels of residual alkaline catalyst (Pitakpoolsil and Hunsom, 2013). Wastewater from mining processes usually has low pH (Oncel et al., 2013).

Aside from the cellulose, hemicelluloses and lignin, lignocellulosic materials contain a variety of low molecular weight organic compounds, called extractives. Example of these extractives is fatty acids, resin acids, and waxes. (Mimms et al., 1993). Part of these extractives may account for the dissolved organic in water.

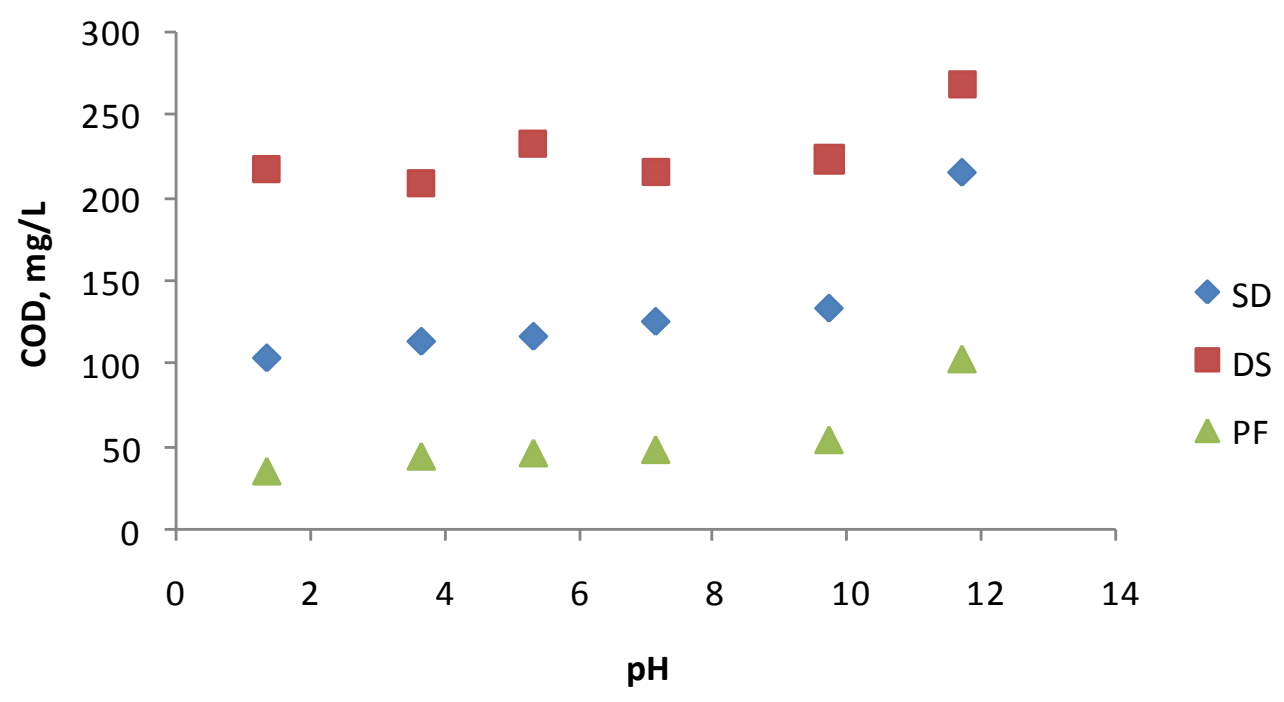

Figure 4. Effect of $\mathrm{pH}$ on COD leached to the water

\subsection{Effect of adsorbent particle size}

Figures 5 and 6 illustrate the relation between particle size of the adsorbent and leaching extent for both TDS and COD. It is clear that the highest leaching of dissolved solids and COD takes place for the smaller particle size of adsorbent. This is due to the increase of surface area by decreasing particle size which facilitates the leaching process. For PF and SD, the values of COD and TDS do not show the same clear significant difference when changing the particle size as DS, however there is a trend of increasing COD and TDS values when decreasing sorbent particle. The same order that was obtained for the previous two properties (dose of adsorbent and pH of water) was kept here. DS has the highest leaching ability, followed by SD and PF 


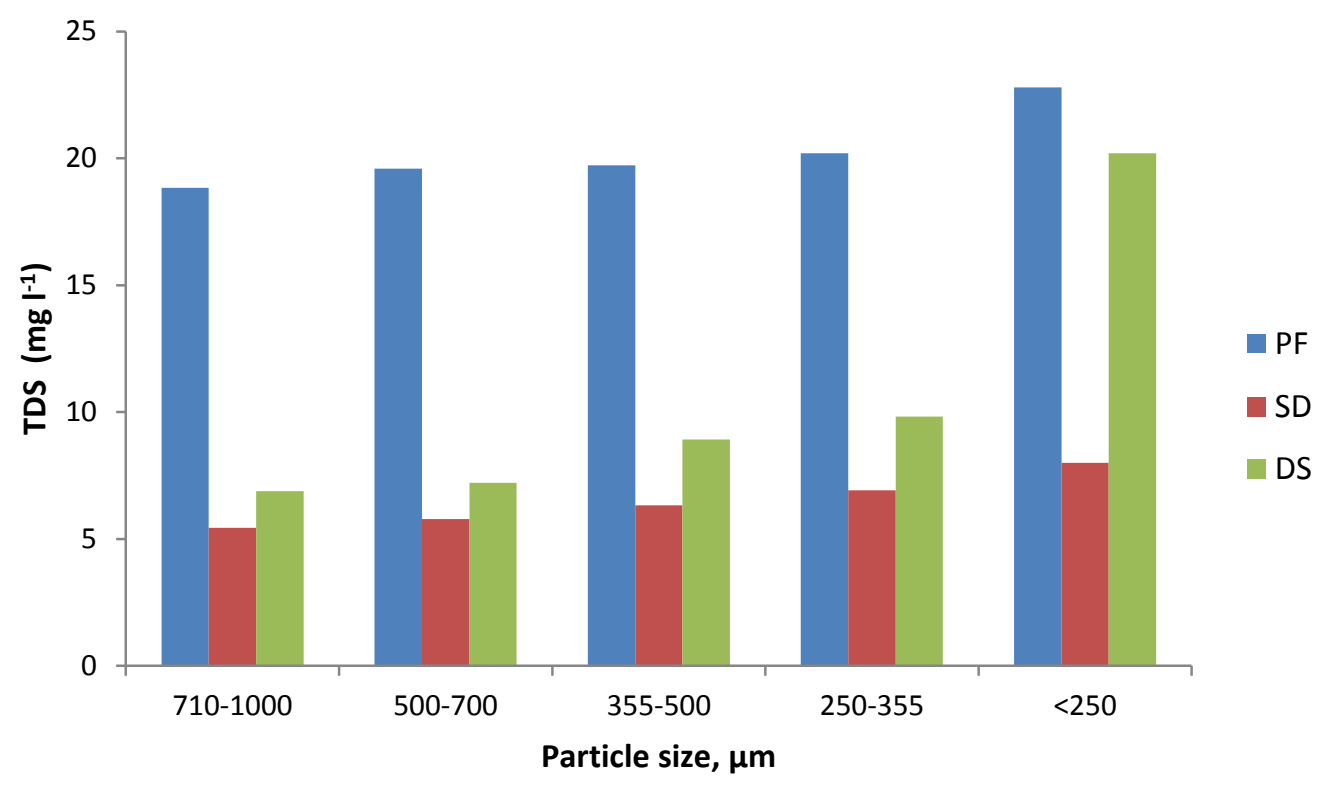

Figure 5. Effect of adsorbent particle size on TDS change of the water

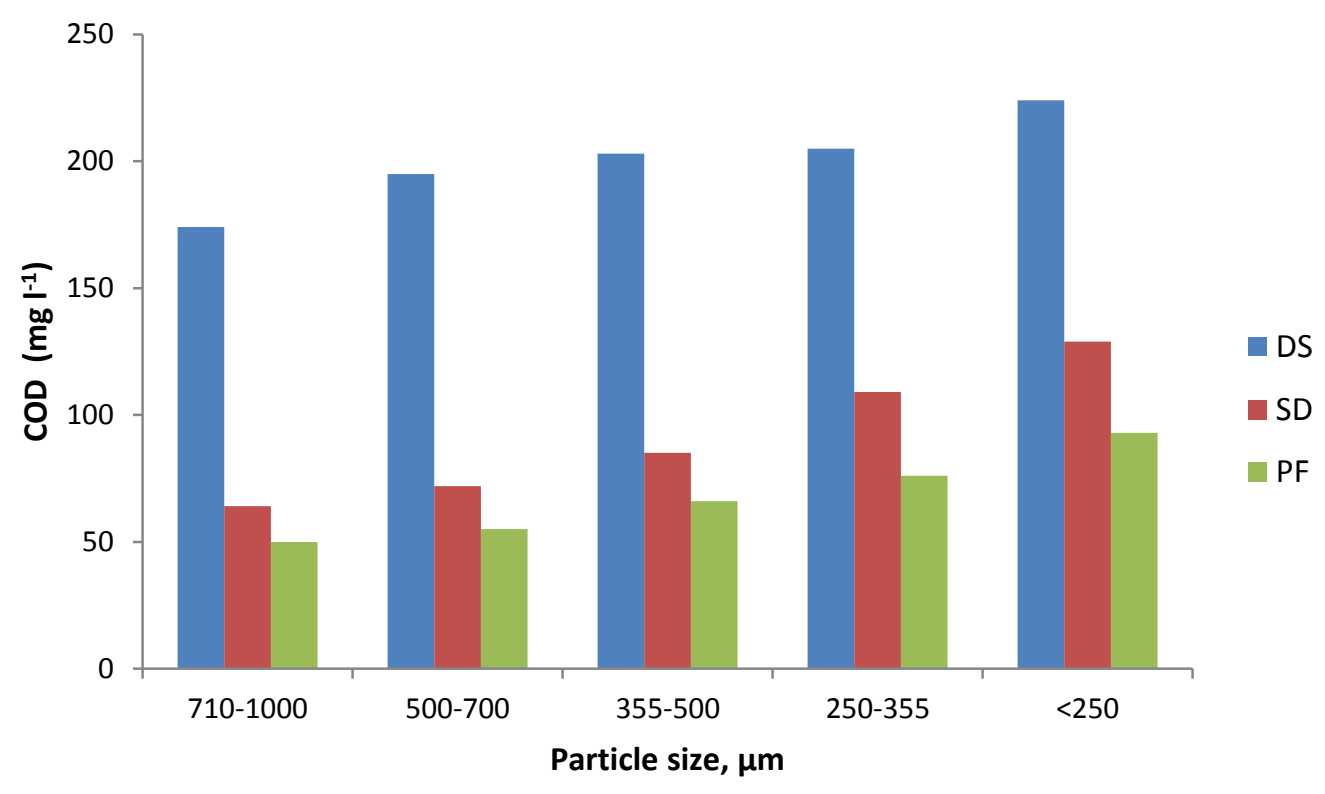

Figure 6. Effect of adsorbent particle size on COD leached to the water

\section{Conclusion}

By examining the extraction behavior of TDS and COD from the tested agricultural wastes to the aqueous solution it can be concluded that under the study conditions all the tested adsorbent are capable of polluting the treated water by TDS and COD. The dose of adsorbent is directly proportional to the concentration of TDS and COD introduced to the water. These concentrations are highly increased at high 
alkaline $\mathrm{pH}$ of the aqueous media and small particle sizes of the adsorbent. More study is required to study this process using other adsorbents and at different working conditions.

\section{References}

Ahmad F., Daud W.M.A.W., Ahmad M.A. and Radzi R. (2012), Cocoa (Theobroma cacao) shell-based activated carbon by $\mathrm{CO}_{2}$ activation in removing of Cationic dye from aqueous solution: Kinetics and equilibrium studies, Chemical Engineering Research and Design, 90, 1480-1490.

Ahmaruzzaman M. (2008), Adsorption of phenolic compounds on low-cost adsorbents: A review, Advanced Colloid Interface Science, 143(1-2), 48-67.

Anagnostopoulos V. and Symeopoulos B. (2013), Sorption of europium by malt spent rootlets, a low cost biosorbent: effect of $\mathrm{pH}$, kinetics and equilibrium studies, Journal of Radionalytical and Nuclear Chemistry, 295, 7-13

Anagnostopoulos V., Manariotis I.D. and Karapanagioti H.K. (2012), Removal of mercury from aqueous solutions by malt spent rootlets, Chemical Engineering Journal, 213, 135-141.

Ansari R. and Mosayebzadeh Z. (2010), Removal of basic dye methylene blue from aqueous solutions using sawdust and sawdust coated with polypyrrole, Journal of the Iranian Chemical Society, 7(2), 339-350.

Auta M. and Hameed B.H. (2013), Coalesced chitosan activated carbon composite for batch and fixed-bed adsorption of cationic and anionic dyes, Colloids Surf B Biointerfaces, 105, 199-206.

Bansal M., Singh D., Garg V.K. and Rose P. (2009), Use of Agricultural Waste for the Removal of Nickel lons from Aqueous Solutions: Equilibrium and Kinetics Studies, International journal of civil and environmental and environmental engineering,1(2), 108-114.

Bhatnagar A. and Minocha A.K. (2006), Conventional and non-conventional adsorbents for removal of pollutants from water- A review, Indian Journal of Chemical Technology, 13, 203-217.

Borrega M., Tolonen L.K. , Bardot F., Testova L. and Sixta H. (2013), Potential of hot water extraction of birch wood to produce high-purity dissolving pulp after alkaline pulping, Bioresource Technology, 135, 665-671.

Browning B. L. (1975). The chemistry of wood. Robert E. Krieger Publishing Company.

Carro L., Anagnostopoulos V., Lodeiro P., Barriada J.L., Herrero R. and De Vicente E.S. (2010) A dynamic proof of mercury elimination from solution through a combined sorption- reduction process, Bioresource Technology, 101(23), 8969-8974.

Chakrabarti S., Chaudhuri B. and Dutta B.K. (2008), Adsorption of model textile dyes from aqueous solutions using agricultural wastes as adsorbents: equilibrium, kinetics and fixed bed column study, International journal of environment and pollution, 34(1-4), 261-274.

Dang V.B.H., Doan H.D., Dang-Vu T. and Lohi A. (2009), Equilibrium and kinetics of biosorption of cadmium(II) and copper(II) ions by wheat straw, Bioresource Technology , 100 (1), 211-219.

Fan L., Luo C., Sun M., Qiu H. and Li X. (2013), Synthesis of magnetic $\beta$-cyclodextrin-chitosan/graphene oxide as nanoadsorbent and its application in dye adsorption and removal, Colloids Surf B Biointerfaces, 103, 601-607.

Galán J., Rodríguez A., Gómez J.M., Allen S.J. and Walker G.M. (2013), Reactive dye adsorption onto a novel mesoporous carbon, Chemical Engineering Journal, 219, 62-68.

Garg U.K., Kaur M.P., Garg V.K. and Sud D. (2008), Removal of Nickel(II) from aqueous solution by adsorption on agricultural waste biomass using a response surface methodological approach, Bioresource Technology, 99,13251331 .

Hach Company (1997), Water Analysis Handbook, Hach Company, Colorado.

Hansen C.L. and Cheong D.Y. (2007), Agricultural Waste Management in Food Processing, in Handbook of Farm, Dairy, and Food Machinery, edited by: Myer Kutz, William Andrew Publishing, US, 609-661, Chapter 20. 
Ismail B., Hussain S.T. and Akram S. (2013), Adsorption of methylene blue onto spinel magnesium aluminate nanoparticles: Adsorption isotherms, kinetic and thermodynamic studies, Chemical Engineering Journal, 219, 395-402.

Jambulingam M., Karthikeyan S., Sivakumar P., Kiruthika J. and Maiyalagan T. (2007), Characteristic study of some activated carbons from agricultural wastes, Journal of Scientific and industrial Research, 66, 495-500.

Jayarajan M., Arunachalam R. and Annadurai G. (2011), Agricultural wastes of jackfruit peel nano-porous adsorbent for removal of rhodamine dye, Asian Journal of Applied Scienc, 4, 263-270.

Johar N., Ahmad I. and Dufresne A. (2012), Extraction, preparation and characterization of cellulose fibres and nanocrystals from rice husk, Industrial Crops and Products, 37 (1), 93-99.

Kalra S.S., Mohan S., Sinha A. and Singh G. (2011), Advanced Oxidation Processes for Treatment of Textile and Dye Wastewater: A Review, 2011 2nd International Conference on Environmental Science and Development IPCBEE, 4, 271-275, Singapore.

Khan N.A., Ibrahim S. and Subramaniam P. ( 2004), Elimination of Heavy Metals from Wastewater Using Agricultural Wastes as Adsorbents, Malaysian Journal of Science, 23, 43 - 51.

Khan T.A., Ali I., Singh V.V. and Sharma S. (2009), Utilization of Fly ash as Low-Cost Adsorbent for the Removal of Methylene Blue, Malachite Green and Rhodamine B Dyes from Textile Wastewater, Journal of Environmental Protection Science, 3, 11-22.

Khan T.A., Singh V.V. and Kumar D. (2004), Removal of some basic dyes from artificial textile wastewater by adsorption on Akash Kinari coal, Journal of Scientific \& Industrial Research, 63, 355-364.

Kılıç M.Y. and Solmaz S.K.A. (2013),Treatment Alternatives of Olive Mill Wastewater (OMW): A Review, Digital Proceeding of the ICOEST'2013 - Cappadocia C.Ozdemir, S. Şahinkaya, E. Kalıpcı, M.K. Oden (editors) Nevsehir, Turkey, June $18-21$.

Koyuncu H., Yildiz N., Salgin U., Koroglu F. and Calimli A. (2011), Adsorption of o-, m- and p-nitrophenols onto organically modified bentonites, Journal of Hazardous Materials, 185(2-3), 1332-1339.

Lai L.W. and Idris A. (2013), Disruption of Oil Palm Trunks and Fronds by Microwave-Alkali Pretreatment, BioResources, 8(2), 2792-2804.

Madrakian T., Afkhami A. and Ahmadi M. (2012), Adsorption and kinetic studies of seven different organic dyes onto magnetite nanoparticles loaded tea waste and removal of them from wastewater samples, Specrtochemimica Acta Part A: Molecular and Biomolecular Spectroscopy, 99, 102-109.

Mimms A., Kocurek M., Pyatte J.A. and Wright E.E. (1993), Kraft Pulping. A Compilation of Notes. TAPPI Press, 6-7.

Moussavi G. and Khosravi R. (2011), The removal of cationic dyes from aqueous solutions by adsorption onto pistachio hull waste, Chemical Engineering Research and Design, 89(10), 2182-2189.

Mundhe K.S., Gaikwad A.B., Torane R.C., Deshpande N.R. and Kashalkar R.V. (2012), Adsorption of methylene blue from aqueous solution using Polyalthia longifolia (Ashoka) seed powder, Journal of Chemical and Pharmaceutical Research, 4(1), 423-436.

Muthukumaran K. and Beulah S.S. (2010), SEM and FT-IR studies on adsorption of mercury (II) and chromium (VI) from wastewater using chemically activated Syzygium jambolanum nut carbon, Asian Journal of Chemistry, 22(10), 7857-7864.

Oncel M.S., Muhcu A., Demirbas E. and Kobya M. (2013), A comparative study of chemical precipitation and electrocoagulation for treatment of coal acid drainage wastewater, Journal of Environmental Chemical Engineering, 1, 989-995.

Pitakpoolsil W. and Hunsom M. (2013), Adsorption of pollutants from biodiesel wastewater using chitosan flakes, Journal of the Taiwan Institute of Chemical Engineers, 44, 963-971.

Qian F., Sun X. and Liu Y. (2013), Removal characteristics of organics in bio-treated textile wastewater reclamation by a stepwise coagulation and intermediate $\mathrm{GAC/}$ оз oxidation process, Chemical Engineering Journal, 214, 112-118. 
Rathinam A., Maharshi B., Janardhanan S.K., Jonnalagadda R.R. and Nair B.U. (2010), Biosorption of cadmium metal ion from simulated wastewaters using Hypnea valentiae biomass: A kinetic and thermodynamic study, Bioresource Technology, 101(5), 1466-1470.

Salati S., Quadri G., Tambone F. and Adani F. (2010), Fresh organic matter of municipal solid waste enhances phytoextraction of heavy metals from contaminated soil, Environmental Pollution, 158, 1899-1906.

Sheela T., Nayaka Y.A., Viswanatha R., Basavanna S. and Venkatesha T.G. (2012), Kinetics and thermodynamics studies on the adsorption of $\mathrm{Zn}(\mathrm{II}), \mathrm{Cd}(\mathrm{II})$ and $\mathrm{Hg}(\mathrm{II})$ from aqueous solution using zinc oxide nanoparticles, Powder Technology, 217, 163-170.

Suksabye P. and Thiravetyan P. (2012), $\mathrm{Cr}(\mathrm{VI})$ adsorption from electroplating plating wastewater by chemically modified coir pith, Journal of Environmental Management, 102, 1-8.

Varga M., Takács M., Záray G. and Varga I. (2013), Comparative study of sorption kinetics and equilibrium of chromium (VI) on charcoals prepared from different low-cost materials, Microchemical Journal, 107, 25-30.

Wahab R., Mustafa M.T., Salam M.A., Sudin M., Samsi H.W. and Rasa M.S.M. (2013), Chemical Composition of Four Cultivated Tropical Bamboo in Genus Gigantochloa, Journal of Agricultural Science, 5(8), 66-76.

Wyman C.E., Decker S.R., Himmel M.E., Brady J.W., C.E. and Viikari L. (2005), Hydrolysis of cellulose and hemicellulose, in "Polysaccharides: Structural Diversity and Functional Versatility", Second Edition, Chapter 43, pp. 995-1034, Marcel Dekker, New York, editted by Severian Dumitriu.

Yan L., Wang Y., Li J., Ma H., Liu H., Li T. and Zhang Y. (2014), Comparative study of different electrochemical methods for petroleum refinery wastewater treatment, Desalination, 341, 87-93.

Zhang H., Wu X. and Li X. (2012), Oxidation and coagulation removal of COD from landfill leachate by Fered-Fenton process, Chemical Engineering Journal, 210, 188-194. 